\title{
Editorial
}

\section{Spinal Motion Preservation Surgery}

\author{
Jau-Ching Wu, ${ }^{1,2}$ Patrick C. Hsieh, ${ }^{3}$ Praveen V. Mummaneni, ${ }^{4}$ and Michael Y. Wang ${ }^{5}$ \\ ${ }^{1}$ Department of Neurosurgery, Taipei Veterans General Hospital, Taipei, Taiwan \\ ${ }^{2}$ School of Medicine, National Yang-Ming University, Taipei, Taiwan \\ ${ }^{3}$ Department of Neurosurgery, University of Southern California, Los Angeles, CA, USA \\ ${ }^{4}$ Department of Neurological Surgery, University of California San Francisco, San Francisco, CA, USA \\ ${ }^{5}$ Department of Neurosurgery, University of Miami, Coral Gables, FL, USA \\ Correspondence should be addressed to Jau-Ching Wu; jauching@gmail.com
}

Received 3 December 2015; Accepted 16 December 2015

Copyright (C) 2015 Jau-Ching Wu et al. This is an open access article distributed under the Creative Commons Attribution License, which permits unrestricted use, distribution, and reproduction in any medium, provided the original work is properly cited.

The principals of spinal surgery include decompression of neural elements, stabilization of motion segments, and balancing the vertebral alignment. Common operations involve resection of the herniated disc or removal of osteophytes and sometimes stabilization of spondylolisthesis. In extreme cases, for example, correction of scoliosis, fixation of multiple spinal segments and intended bone fusion are often necessary and inevitable, because only arthrodesis can maintain the surgical outcomes for a prolonged time. However, arthrodesis inevitably causes a loss in the range of physiological motion of the spinal segments and consequently may lead to multiple problems, including stiffness, junctional kyphosis, and increased risk of adjacent segment disease (ASD). In the area of spinal surgery during the last decade, much attention therefore has been directed to motion preservation. There are multiple techniques and devices aimed at preserving the segmental range of motion in the treated spine, including disc or facet arthroplasty, laminoplasty, pedicle based dynamic stabilization, and interspinous devices [1-7].

To date, among these innovative surgical approaches to preserve spinal motion, cervical disc arthroplasty (CDA) has the most data on its use and effectiveness. Several multicenter, prospective, randomized, and controlled clinical trials have demonstrated equivalent or superior clinical results of CDA when compared with standard anterior cervical discectomy and fusion (ACDF) [8-11]. Most of the implanted artificial discs have functioned well to maintain a physiological range of motion at the indexed levels [12-14]. However, there has not been enough evidence for the theoretical benefit of CDA on decreasing ASD. Even the true incidence of ASD or its etiologies remain elusive. A study of a cohort of 19,385 patients who underwent ACDF estimated the annual incidence of ASD to be $0.8 \%$, and the accumulative reoperation rate after ACDF was $5.6 \%$ in ten years [15]. Although motion preservation surgery of the spine avoids the compensatory increase in the work load at the adjacent levels after spinal arthrodesis surgery, whether ASD can be decreased or postponed by spinal motion preservation surgery remains uncertain. Due to the relatively low incidence rate of ASD, more studies with a larger number of patients and longer term follow-up are required to clarify the outcomes and effects of surgery that preserves spinal motion.

Surgery aiming to preserve motion of the lumbar spine has generated much attention and concern. The lumbar spine inherently endures more weight than the cervical spine and thus makes stabilization as well as preservation of motion even more challenging. Lumbar disc arthroplasty (LDA), in several clinical trials, demonstrated similar improvement in clinical outcomes to spinal fusion surgery $[16,17]$. However, there were not sufficient data to support the reduction of ASD after LDA. Moreover, there was less evidence of satisfactory long term outcomes from LDA than has been shown with cervical disc replacement. As there were additional problems related to the approach and difficulty in retrieval, LDA did not gain similar popularity to CDA in the past decade [18].

Others tried pedicle based dynamic stabilization devices since they reportedly provided limited segmental motion and decreased stiffness, but some of these pedicle screws became 
loose during follow-up $[2,5,7]$. A few studies demonstrated satisfactory clinical outcomes of these dynamic pedicle screws in lumbar degenerative disc disease (DDD) and mild spondylolisthesis $[1,2,5,7]$. However, the role of lumbar dynamic devices is still debated and is not well accepted.

Another attempt at nonfusion fixation in the lumbar spine was the use of interspinous devices. However, interspinous devices typically led to postoperative focal kyphosis with various degrees of stability provided, depending on its design [19].

The major concerns of these lumbar dynamic devices are the indications for surgery and the durability of the surgery. There are still many debates on the best candidates for such kinds of motion preservation surgery on the lumbar spine. Patients with DDD were the most commonly proposed candidates for these dynamic devices. Nonetheless, it is uncertain if these devices are effective not only for those with DDD but also for others who suffer from disc herniation, hypertrophic ligaments, facet arthropathy, spondylolisthesis, and scoliosis. Such dynamic devices inevitably have wearing problems and lack long term results.

Furthermore, the spinal-pelvic alignment has not been well studied for motion preservation surgery in the lumbar spine. The importance of sagittal balance learned from fusion surgery for deformity has not been translated to or not corroborated for dynamic devices.

In this special issue, there are five papers addressing these state-of-art applications of spinal motion preservation surgery. The papers cover review of material science of CDA, new assessment of three-dimensional movements in lumbar facet joints and vertebrae in patients who underwent LDA, long term (up to almost 9 years) outcomes of cervical laminoplasty in the elderly, comparison of vertebral body stapling and bracing for patients with idiopathic scoliosis, and analysis of lumbar lordosis on screw loosening in Dynesys dynamic stabilization. Although many of these technologies have been on the market for years, more studies are necessary to investigate the long term effects and address the avoidance of associated complications before greater expansion of their utilization.

\section{Jau-Ching Wu \\ Patrick C. Hsieh \\ Praveen V. Mummaneni Michael Y. Wang}

\section{References}

[1] L. Fay, J. Wu, T. Tsai et al., "Intervertebral disc rehydration after lumbar dynamic stabilization: magnetic resonance image evaluation with a mean followup of four years," Advances in Orthopedics, vol. 2013, Article ID 437570, 8 pages, 2013.

[2] L.-Y. Fay, J.-C. Wu, T.-Y. Tsai, C.-L. Wu, W.-C. Huang, and H. Cheng, "Dynamic stabilization for degenerative spondylolisthesis: evaluation of radiographic and clinical outcomes," Clinical Neurology and Neurosurgery, vol. 115, no. 5, pp. 535-541, 2013.

[3] G. Gandhoke, J.-C. Wu, N. C. Rowland, S. A. Meyer, C. Gupta, and P. V. Mummaneni, "Anterior corpectomy versus posterior laminoplasty: Is the risk of postoperative C-5 palsy different?" Neurosurgical Focus, vol. 31, no. 4, p. E12, 2011.
[4] P. Khoueir, K. A. Kim, and M. Y. Wang, "Classification of posterior dynamic stabilization devices," Neurosurgical Focus, vol. 22, article E3, 2007.

[5] C.-C. Ko, H.-W. Tsai, W.-C. Huang et al., "Screw loosening in the Dynesys stabilization system: radiographic evidence and effect on outcomes," Neurosurgical Focus, vol. 28, no. 6, p. E10, 2010.

[6] S. A. Meyer, J.-C. Wu, and P. V. Mummaneni, "Laminoplasty outcomes: is there a difference between patients with degenerative stenosis and those with ossification of the posterior longitudinal ligament?" Neurosurgical Focus, vol. 30, article E9, 2011.

[7] J.-C. Wu, W.-C. Huang, H.-W. Tsai et al., "Pedicle screw loosening in dynamic stabilization: incidence, risk, and outcome in 126 patients," Neurosurgical Focus, vol. 31, no. 4, article E9, 2011.

[8] J. K. Burkus, V. C. Traynelis, R. W. Haid, and P. V. Mummaneni, "Clinical and radiographic analysis of an artificial cervical disc: 7-year follow-up from the Prestige prospective randomized controlled clinical trial," Journal of Neurosurgery: Spine, vol. 21, no. 4, pp. 516-528, 2014.

[9] D. Coric, P. K. Kim, J. D. Clemente, M. O. Boltes, M. Nussbaum, and S. James, "Prospective randomized study of cervical arthroplasty and anterior cervical discectomy and fusion with longterm follow-up: results in 74 patients from a single site," Journal of Neurosurgery: Spine, vol. 18, no. 1, pp. 36-42, 2013.

[10] P. V. Mummaneni, B. Y. Amin, J.-C. Wu, E. D. Brodt, J. R. Dettori, and R. C. Sasso, "Cervical artificial disc replacement versus fusion in the cervical spine: a systematic review comparing long-term follow-up results from two FDA trials," EvidenceBased Spine-Care Journal, vol. 3, no. 1, pp. 59-66, 2012.

[11] C. D. Upadhyaya, J.-C. Wu, G. Trost et al., "Analysis of the three united states food and drug administration investigational device exemption cervical arthroplasty trials," Journal of Neurosurgery: Spine, vol. 16, no. 3, pp. 216-228, 2012.

[12] L.-Y. Fay, W.-C. Huang, T.-Y. Tsai et al., "Differences between arthroplasty and anterior cervical fusion in two-level cervical degenerative disc disease," European Spine Journal, vol. 23, no. 3, pp. 627-634, 2014.

[13] J.-C. Wu, W.-C. Huang, T.-H. Tu et al., "Differences between soft-disc herniation and spondylosis in cervical arthroplasty: CT-documented heterotopic ossification with minimum 2 years of follow-up," Journal of Neurosurgery: Spine, vol. 16, no. 2, pp. 163-171, 2012.

[14] J. C. Wu, S. A. Meyer, and G. Gandhoke, "PRESTIGE cervical arthroplasty: past, present, and future," Seminars in Spine Surgery, vol. 24, no. 1, pp. 14-19, 2012.

[15] J.-C. Wu, L. Liu, H. Wen-Cheng et al., “The incidence of adjacent segment disease requiring surgery after anterior cervical diskectomy and fusion: estimation using an 11-year comprehensive nationwide database in Taiwan," Neurosurgery, vol. 70, no. 3, pp. 594-601, 2012.

[16] W. C. H. Jacobs, N. A. van der Gaag, M. C. Kruyt et al., "Total disc replacement for chronic discogenic low back pain: a Cochrane review," Spine, vol. 38, no. 1, pp. 24-36, 2013.

[17] P. C. McAfee, B. Cunningham, G. Holsapple et al., "A prospective, randomized, multicenter Food and Drug Administration investigational device exemption study of lumbar total disc replacement with the CHARITE artificial disc versus lumbar fusion: part II: evaluation of radiographic outcomes and correlation of surgical technique accuracy with clinical outcomes," Spine, vol. 30, no. 14, pp. 1576-1583, E388-E390, 2005. 
[18] J.-C. Wu, T.-H. Tu, and P. V. Mummaneni, "Spinal arthroplasty: differences between the cervical and lumbar spine," World Neurosurgery, vol. 78, no. 3-4, pp. 245-246, 2012.

[19] J.-C. Wu and P. V. Mummaneni, "Using lumbar interspinous anchor with transforaminal lumbar interbody fixation," World Neurosurgery, vol. 73, no. 5, pp. 471-472, 2010. 


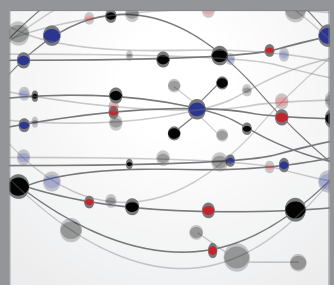

The Scientific World Journal
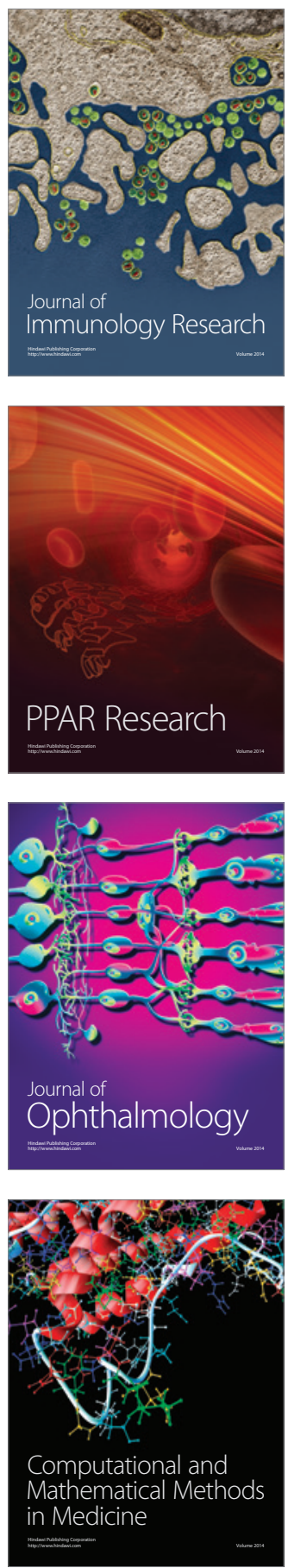

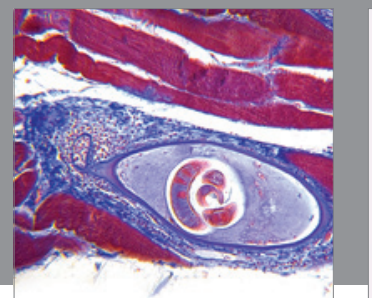

Gastroenterology

Research and Practice
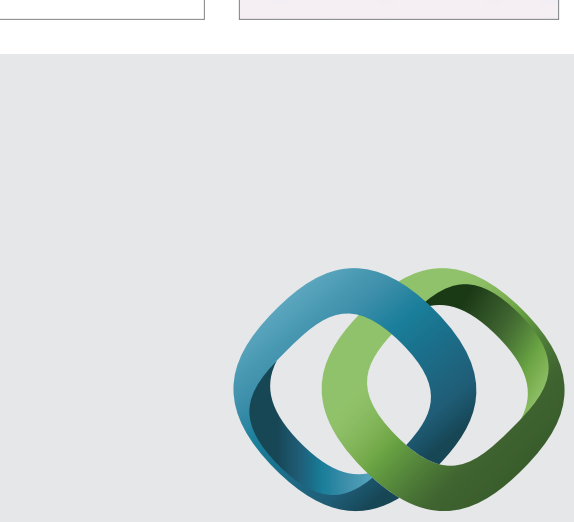

\section{Hindawi}

Submit your manuscripts at

http://www.hindawi.com
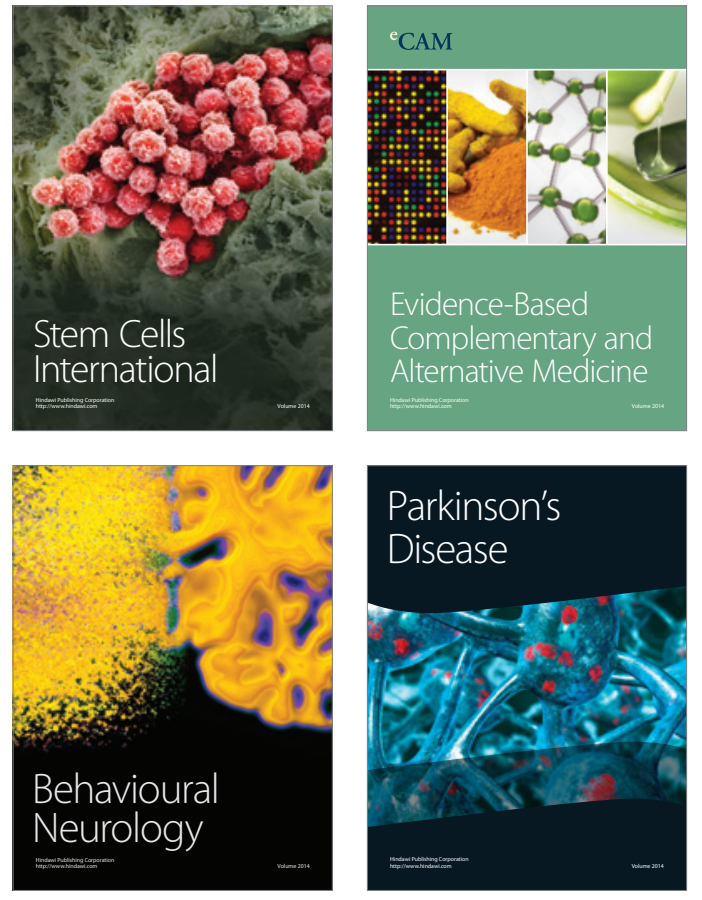
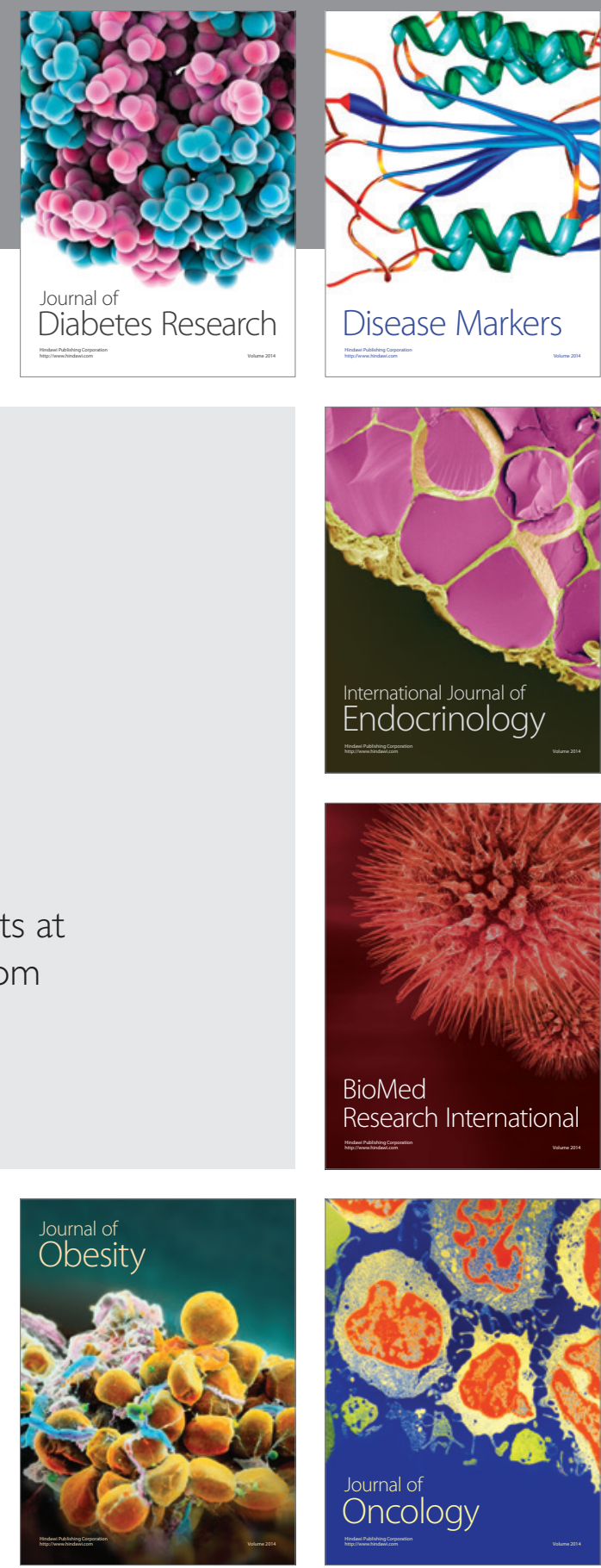

Disease Markers
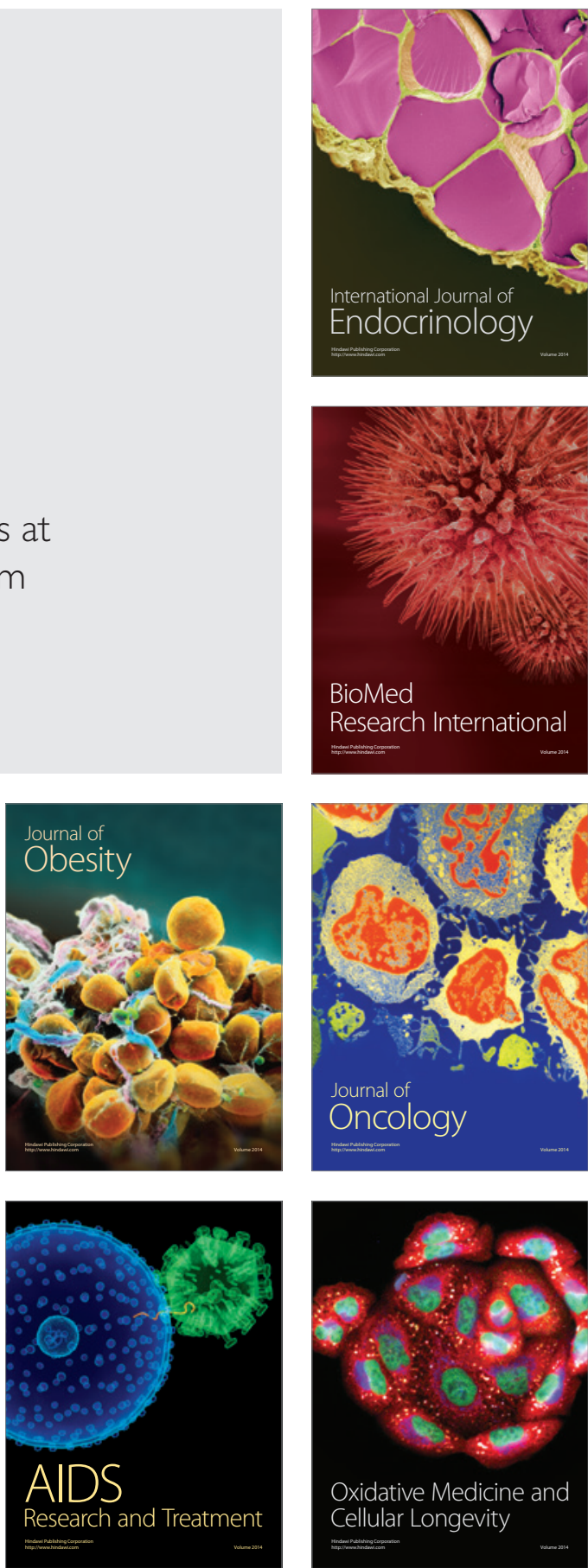